\title{
Validación de una encuesta telefónica para el diagnóstico de depresión en ancianos
}

Validation of a Telephone-administered Geriatric Depresión Scale in a Hispanic Elderly Population. Carrete P, Augustovski F, Gimpel Net al. J Gen Intern Med 2001;16:446-450.

\section{Objetivo}

Desarrollar y validar una versión telefónica en castellano de la "Geriatric Depresión Scale" (GDS)

\section{Diseño}

Estudio transversal.

\section{Lugar}

Unidad de Medicina Familiar y Preventiva del Hospital Italiano de Buenos Aires, Argentina.

\section{Pacientes}

Se tomó una muestra aleatoria de 282 pacientes mayores de 65 años pertenecientes a un sistema pre-pago. Se incluyeron los paciente capaces de contestar una entrevista telefónica sin ayuda.

\section{Descripción de los tests en estudio y del test de referencia} EI GDS es un cuestionario simple de 30 preguntas que se responden en forma afirmativa o negativa (ver tabla 1). El puntaje final puede ir de 0 a 30. Valores mayores de 10-11 se consideran diagnósticos de depresión. El instrumento original está en inglés. Fue traducido por dos observadores independientes y luego traducido "hacia atrás" * nuevamente al inglés para asegurar que la versión en español no haya cambiado el sentido de las preguntas. EI GDS se aplicó en forma telefónica (GDS-T) y por entrevista personal (GDS-P).

El test de referencia utilizado fue la entrevista personal aplicando criterios del DSM IV para el diagnóstico de depresión.
Tabla 1 - Cuestionario de escala de depresión geriátrica (GDS)

1. ¿Está usted básicamente satisfecho con su vida?

2. ¿Ha abandonado muchas de sus actividades o elementos de interés?

3. ¿Siente usted que su vida está vacía?

4. ¿Se siente aburrido a menudo?

5. ¿Está usted esperanzado con respecto a su futuro?

6. ¿Se siente usted molesto por pensamientos que no puede quitar de su mente?

7. ¿Se siente usted de buen ánimo la mayoría del tiempo?

8. ¿Está usted temeroso de que algo malo vaya a ocurrirle?

9. ¿Se siente usted feliz la mayor parte del tiempo?

10. ¿Se siente usted abandonado?

11. ¿Se siente usted inquieto y nervioso a menudo?

12. ¿Prefiere usted permanecer en su casa más que salir o hacer cosas nuevas?

13. ¿Está usted frecuentemente preocupado por el futuro?

14. ¿Siente usted que tiene más problemas con su memoria que la mayoría de la gente?

\section{Medición de Resultados}

Porcentaje de personas con diagnóstico de depresión a través de los distintos métodos. Sensibilidad y especificidad de la GDS-T y GDS-P para el diagnóstico de depresión. Correlación de los resultados de la GDS-T y GDS-P.

\section{Resultados}

De las 282 personas elegidas al azar, $30(11 \%)$ se negaron a participar. De las 252 que completaron el GDS-T, 169 (67\%) concurrieron para una entrevista personal donde se realizó el GDSP. El grupo que no concurrió a la entrevista era similar al resto en edad, sexo y estado civil. La prevalencia de depresión en el grupo que completó ambos cuestionarios fue $12,8 \%$ utilizando GDS-P y 14,9\% usando GSD-T. El grupo que completó sólo el GDS-T presentó una mayor prevalencia de depresión (22,7\%, p0.01).

\section{Tabla 2 - Resultados principales}

\begin{tabular}{l|l|l|l}
\hline Instrumento & Alpha Cronhach* & Sensibilidad & Especilicidad \\
\hline GDS-T & 0,88 & $84 \%$ & $79 \%$ \\
\hline GDS-P & 0,85 & $88 \%$ & $82 \%$ \\
\hline
\end{tabular}

La correlación ${ }^{\star}$ entre los valores del GDS-T y GDS-P fue 0,85

\section{Conclusión}

El GDS-T presentó buena consistencia interna (alpha Cronbach) y correlación elevada con el GDS-P por lo que podría ser un buen instrumento en español para rastreo de depresión en ancianos.

15. ¿Piensa usted que es maravilloso estar vivo ahora?

16. ¿Se siente usted descorazonado y triste a menudo?

17. ¿Se siente usted actualmente inútil?

18. ¿Se preocupa usted un montón acerca del pasado?

19. ¿Encuentra usted la vida bastante estimulante?

20. ¿Es difícil para usted encarar nuevos proyectos?

21. ¿Se siente usted lleno de energía?

22. ¿Siente usted que su situación es desesperante?

23. ¿Piensa que la mayoría de las personas está mejor que usted?

24. ¿Se siente usted frecuentemente perturbado por las pequeñas cosas?

25. iSe siente frecuentemente con deseos de llorar?

26. ¿Tiene usted problemas para concentrarse?

27. ¿Disfruta levantándose por la mañana?

28. ¿Prefiere evitar los encuentros sociales?

29. ¿Es fácil para usted tomar decisiones?

30. ¿Está su mente clara como solía estarlo?

Fuente de financiamiento: Fundación MF, Argentina.

\section{Comentario}

Un cuarto de los pacientes ancianos que consultan al médico de atención primaria presentan síntomas depresivos. Los resultados clínicos en estos pacientes no parecen haber mejorado a pesar de los esfuerzos realizados durante los últimos 20 años. La investigación sobre actitudes de los médicos, tratamientos eficaces para la depresión menor, y maneras de identificar barreras específicas para adhesión al tratamiento en pacientes añosos son de gran utilidad. La baja sospecha y el sub-tratamiento de depresión son problemas universales en atención primaria. ${ }^{1}$ Los esfuerzos actuales por mejorar el reconocimiento han incluido el desarrollo de instrumentos diagnósticos y programas educativos entre otras medidas. El "Geriatric Depresión Scale" (GDS) fue desarrollado para ayudar a los médicos a reconocer los síntomas depresivos en ancianos tanto en pacientes internados como ambulatorios. ${ }^{2}$ Los autores realizaron una traducción del instrumento con la técnica recomendada y presentan los primeros datos de confiabili- dad y validez de esta versión del GDS en español. Una limitación del trabajo fue que la población estudiada está conformada en su mayoría por personas de medianos ingresos que viven en zonas urbanas, por lo tanto debemos ser cautos si deseamos extrapolar los resultados a poblaciones diferentes (Ej: zonas rurales)

Un valioso aporte de este trabajo es que la administración telefónica del cuestionario hace posible su aplicación como método de rastreo para pacientes que no consultan. Sin embargo, para decidir utilizar un instrumento con esta finalidad, al igual que en otras patologías, la investigación debe analizar una mejora en los resultados clínicos. No hay suficiente evidencia para recomendar la práctica de rastreo para depresión en pacientes ancianos que no consultan.

El tener datos de confiabilidad y validez en población argentina de un instrumento sencillo, de rápida aplicación y fácil interpretación para el diagnóstico de depresión en ancianos es altamente promisorio.

Dra. Marina Khoury [ Medicina Interna General ]

\section{Referencias}

1- MetzgerBE, Coustan DR.Summary and Recommendations of the fourth International Workshop-Conference on Gestational Diabetes.Diabetes Care 1998;21:supl 2: 161-167. 2- Diabetes and Pregnancy. ACOG technical bulletin № 200. Washington D.C: American College of Obstetricians and Gynecologists, December 1994: $359-66$. 3- Elliot BD Schenker S, Langer O. Comparative placental transport of oral hypoglycemic agents in humans: a model of human placental transfer. Am J Obstet Gynecol 1994;171:653-60 4- Greene MF: Oral hypoglycemic drugs for Gestational Diabetes. N Engl J Med. 2000, 16: 1178. 